\title{
Cost-Effectiveness of Rate- and Rhythm-Control Drugs for Treating Atrial Fibrillation in Korea
}

\author{
Min Kim ${ }^{1 *}$, Woojin $\mathrm{Kim}^{2 *}$, Changsoo Kim ${ }^{2,3}$, and Boyoung Joung \\ ${ }^{1}$ Division of Cardiology, Department of Internal Medicine, Severance Cardiovascular Hospital, Yonsei University College of Medicine, Seoul; \\ ${ }^{2}$ Department of Preventive Medicine, Yonsei University College of Medicine, Seoul; \\ ${ }^{3}$ Institute of Human Complexity and Systems Science, Yonsei University, Seoul, Korea.
}

Purpose: Although the economic and mortality burden of atrial fibrillation $(\mathrm{AF})$ is substantial, it remains unclear which treatment strategies for rate and rhythm control are most cost-effective. Consequently, economic factors can play an adjunctive role in guiding treatment selection.

Materials and Methods: We built a Markov chain Monte Carlo model using the Korean Health Insurance Review \& Assessment Service database. Drugs for rate control and rhythm control in AF were analyzed. Cost-effective therapies were selected using a cost-effectiveness ratio, calculated by net cost and quality-adjusted life years (QALY).

Results: In the National Health Insurance Service data, 268149 patients with prevalent AF (age $\geq 18$ years) were identified between January 1, 2013 and December 31, 2015. Among them, 212459 and 55690 patients were taking drugs for rate and rhythm control, respectively. Atenolol cost \$714/QALY. Among the rate-control medications, the cost of propranolol was lowest at \$487/QALY, while that of carvedilol was highest at \$1363/QALY. Among the rhythm-control medications, the cost of pilsicainide was lowest at \$638/QALY, while that of amiodarone was highest at \$986/QALY. Flecainide and propafenone cost \$834 and \$830/QALY, respectively. The cost-effectiveness threshold of all drugs was lower than $\$ 30000 /$ QALY. Compared with atenolol, the rate-control drugs propranolol, betaxolol, bevantolol, bisoprolol, diltiazem, and verapamil, as well as the rhythm-control drugs sotalol, pilsicainide, flecainide, propafenone, and dronedarone, showed better incremental cost-effectiveness ratios.

Conclusion: Propranolol and pilsicainide appear to be cost-effective in patients with AF in Korea assuming that drug usage or compliance is the same.

Key Words: Atrial fibrillation, drugs, cost effectiveness, QALY

\section{INTRODUCTION}

Atrial fibrillation (AF), the most common cardiac dysrhythmia,

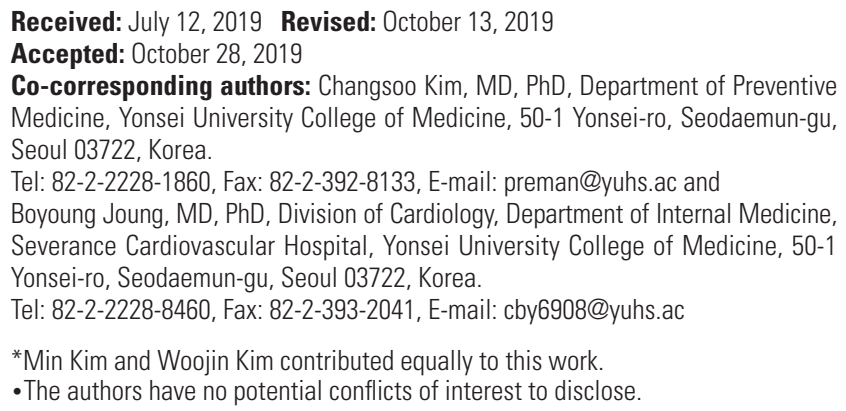
mons Attribution Non-Commercial License (https://creativecommons.org/licenses/ by-nc/4.0) which permits unrestricted non-commercial use, distribution, and reproduction in any medium, provided the original work is properly cited. causes substantial morbidity. ${ }^{1-4} \mathrm{AF}$ affects millions of patients and increases one's risk of heart failure, ${ }^{5,6}$ stroke, ${ }^{7,8}$ and death., ${ }^{2,5}$ The prevalence of AF increases with advancing age, and the older adult population is increasing worldwide. ${ }^{9-14}$ The prevalence of AF in Korea was 1.53\% in 2015 and was reported as likely to increase to $5.81 \%$ by $2060 .{ }^{15}$ Given these findings, an increasing economic burden of AF on the health care system is anticipated, and it is important to estimate the cost and effectiveness of different therapeutic options. ${ }^{10,16}$

Several studies recently compared the economic practicality of non-vitamin $\mathrm{K}$ antagonist oral anticoagulants to adjusteddose warfarin for the prevention of stroke in $\mathrm{AF}^{17-20} \mathrm{It}$ is known that rate-control and rhythm-control drugs do not show significant differences in mortality rates. ${ }^{21,22}$ In a previous study in Korea, a rhythm-study strategy also showed no benefit on cardiovascular mortality, compared with a rate-control strategy. ${ }^{23}$ Meanwhile, economic studies comparing AF rate control ver- 
sus rhythm control have revealed that rate control reduces costs, compared with rhythm control, which included electrical cardioversion in Western individuals: The study involved 4060 patient across 213 sites in Canada and the United States, with mean survival, resource use (hospital days, pacemaker procedures, cardioversions, percutaneous transluminal coronary angioplasties, coronary artery bypass graft procedures, valve surgery procedures, ablation, and short-stay and emergency department visits), costs, and cost-effectiveness compared as outcome indicators between rate-control and rhythm-control groups. Rate-control drugs included digoxin, atenolol, metoprolol, propranolol, diltiazem, and verapamil, and rhythm-control drugs included flecainide, propafenone, quinidine, disopyramide, moricizine, amiodarone, sotalol, and dofetilide. Rate-control costs were $\$ 5077$ less per person than those for rhythm control. ${ }^{24}$ However, the cost-effectiveness of treating AF with ratecontrol and rhythm-control strategies has not been examined in Korea. The costs of drugs and hospitalization in Korea are different from those in Western countries. Moreover, recently, hospitalization for AF has increased by $420 \%$ from 767 to 3986 per 1 million Korean populations from 2006 to 2015 and hospitalization for AF control has increased compared with hospitalization for ischemic stroke and myocardial infarction (MI). ${ }^{16}$ Based on these results, cost-effectiveness analysis may play a substantial role in treatment selection. Therefore, we sought to compare the projected quality-adjusted survival and costs of different rate-control and rhythm-control drugs in Korean patients with $\mathrm{AF}$.

\section{MATERIALS AND METHODS}

This study examined data from the National Health Insurance Service (NHIS) database. The NHIS is a single insurer controlled by the Korean government, and the majority (97.1\%) of Korean residents are mandatory subscribers, with the remaining 3\% being medical aid subjects. The sociodemographic information of patients, their use of inpatient and outpatient services, pharmacy dispensing claims, and mortality data were extracted. This study was approved by the Institutional Review Board of Yonsei University Health System (4-2019-0802), which waived the need for informed consent.

\section{Study population}

In the Korean NHIS database, a total of 268149 patients with prevalent $\mathrm{AF}$ who were aged 18 years or older were identified between January 1, 2013 and December 31, 2015. Those with valvular $\mathrm{AF}$, such as moderate to severe mitral valve stenosis and prosthetic valve disease [International Classification of Disease 10th Revision (ICD)-I050, I052, I342] were excluded. Finally, this study included 212459 and 55690 patients who were taking rate-control and rhythm-control drugs, respectively. The rate-control drugs included digoxin, beta-adreno- ceptor antagonists (atenolol, betaxolol, bevantolol, bisoprolol, carvedilol, propranolol), diltiazem, and verapamil, while the rhythm-control drugs included flecainide, propafenone, pilsicainide, amiodarone, sotalol, and dronedarone (Table 1).

AF was diagnosed using ICD-10 codes $\mathrm{I} 48$ (AF and atrial flutter), I48.0 (AF), and I48.1 (atrial flutter). Moreover, patients were defined as having AF only when it was a discharge diagnosis or confirmed more than twice in the outpatient department to ensure diagnostic accuracy. The AF diagnosis was previously validated in the NHIS database with a positive predictive value of $94.1 \%$. A validation study was performed in 628 randomly selected patients with the ICD-10 code I48 at two separate institutions. The patients' electrocardiograms (ECGs) were reviewed by two physicians. Patients were defined as AF if documented by ECG. ${ }^{16,25,26}$

\section{Decision model}

We developed a Markov chain Monte Carlo model to evaluate the cost-effectiveness of the rate- and rhythm-control drugs. Health states modeled included healthy AF, congestive heart failure (CHF), MI, ischemic stroke, transient ischemic attack (TIA), intracranial hemorrhage (ICH), gastrointestinal bleeding (GI), and death. Cases of "fatal" CHF, MI, ischemic stroke, TIA, ICH, and GI bleeding were defined as transition to death.

Table 1. Drugs Used to Treat Atrial Fibrillation in the Rate- and RhythmControl Groups among Patients Newly Diagnosed with Atrial Fibrillation between January 1, 2013 and December 31, 2015 in Korea

\begin{tabular}{|ccccc}
\hline & \multirow{2}{*}{ Total } & \multicolumn{3}{c}{ Years } \\
\cline { 3 - 5 } & & $\mathbf{2 0 1 3}$ & $\mathbf{2 0 1 4}$ & $\mathbf{2 0 1 5}$ \\
\hline Rate control & & & & \\
Overall & $212459(100)$ & $68182(100)$ & $69225(100)$ & $75052(100)$ \\
\hline Digoxin & $39360(17.2)$ & $13235(19.4)$ & $13195(19.1)$ & $12930(17.2)$ \\
\hline Atenolol & $10852(4.2)$ & $4242(6.2)$ & $3449(5.0)$ & $3161(4.2)$ \\
\hline Betaxolol & $928(0.4)$ & $364(0.5)$ & $277(0.4)$ & $287(0.4)$ \\
\hline Bevantolol & $536(0.2)$ & $212(0.3)$ & $172(0.2)$ & $152(0.2)$ \\
\hline Bisoprolol & $49493(23.8)$ & $15410(22.6)$ & $16253(23.5)$ & $17830(23.8)$ \\
\hline Carvedilol & $38412(18.1)$ & $12404(18.2)$ & $12398(17.9)$ & $13610(18.1)$ \\
\hline Propranolol & $32854(16.5)$ & $9998(14.7)$ & $10473(15.1)$ & $12383(16.5)$ \\
\hline Diltiazem & $24096(11.2)$ & $7893(11.6)$ & $7802(11.3)$ & $8401(11.2)$ \\
\hline Verapamil & $4803(2.2)$ & $1695(2.5)$ & $1463(2.1)$ & $1645(2.2)$ \\
\hline Rhythm control & & & & \\
\hline Overall & $55690(100)$ & $16617(100)$ & $18758(100)$ & $20315(100)$ \\
\hline Flecainide & $13914(25.0)$ & $4082(24.6)$ & $4616(24.6)$ & $5216(25.7)$ \\
\hline Propafenone & $14078(25.2)$ & $4196(25.2)$ & $4792(25.6)$ & $5090(25.1)$ \\
\hline Pilsicainide & $2890(5.2)$ & $1058(6.4)$ & $998(5.3)$ & $834(4.1)$ \\
\hline Amiodarone & $21976(39.5)$ & $6547(39.4)$ & $7367(39.3)$ & $8062(39.7)$ \\
\hline Sotalol & $1065(1.9)$ & $324(1.9)$ & $327(1.7)$ & $414(2.0)$ \\
\hline Dronedarone & $1767(3.2)$ & $410(2.5)$ & $658(3.5)$ & $699(3.4)$ \\
\hline
\end{tabular}

Values are presented as $n(\%)$. Reference: The National Health Insurance Service. Nebivolol (2729; $4.0 \%$ in 2013, 3743; $5.4 \%$ in 2014 , and $4653 ; 6.2 \%$ in 2015) was excluded in cost-effectiveness analysis due to incomplete health event records. 
Non-fatal GI bleeding was assumed to be a transition to healthy AF. The health event was defined as newly diagnosed using ICD-10 codes for each event of CHF (I50.0, I11.0), MI (I21, I22), ischemic stroke (I63, I64), TIA (G45), ICH (I60, I61, I62), and GI bleeding (K92.2) within 1 year, considering that the transition cycle in the Markov model was 1 year in patients who had been on medication for more than 6 months after being newly di- agnosed AF. We assumed that the healthy state transitioned annually based on the probability of an independent health event occurring within 1 year. The transition probabilities were estimated by cumulative incidence based on the data of the patients who were enrolled in this study between January 1, 2013 and December 31, 2015 (Table 2, Fig. 1; Supplementary Fig. 1, only online). Drug adherence rates were assumed to be

Table 2. Base-Case Values Used in Sensitivity Analysis of Rate- and Rhythm-Control Drugs among Patients Newly Diagnosed with Atrial Fibrillation between January 1, 2013 and December 31, 2015 in Korea

\begin{tabular}{|c|c|c|c|c|c|c|c|c|c|c|c|c|}
\hline \multirow[b]{2}{*}{ Drugs } & \multicolumn{2}{|c|}{ CHF } & \multicolumn{2}{|c|}{ MI } & \multicolumn{2}{|c|}{ Ischemic stroke } & \multicolumn{2}{|c|}{ TIA } & \multicolumn{2}{|c|}{ ICH } & \multicolumn{2}{|c|}{ GI bleeding } \\
\hline & Event (n) & $\begin{array}{c}\text { Rate } \\
\text { (\%/year) }\end{array}$ & Event (n) & $\begin{array}{c}\text { Rate } \\
\text { (\%/year) }\end{array}$ & Event (n) & $\begin{array}{c}\text { Rate } \\
\text { (\%/year) }\end{array}$ & Event (n) & $\begin{array}{c}\text { Rate } \\
\text { (\%/year) }\end{array}$ & Event (n) & $\begin{array}{c}\text { Rate } \\
\text { (\%/year) }\end{array}$ & Event (n) & $\begin{array}{c}\text { Rate } \\
\text { (\%/year) }\end{array}$ \\
\hline \multicolumn{13}{|l|}{ Rate control } \\
\hline Digoxin (n=39360) & 11238 & 28.6 & 1140 & 2.9 & 3251 & 8.3 & 563 & 1.4 & 367 & 0.9 & 324 & 0.8 \\
\hline Atenolol (n=10852) & 1287 & 11.9 & 200 & 1.8 & 873 & 8.0 & 177 & 1.6 & 115 & 1.1 & 48 & 0.4 \\
\hline Betaxolol (n=928) & 109 & 11.8 & 16 & 1.7 & 58 & 6.3 & 16 & 1.7 & 5 & 0.5 & 6 & 0.7 \\
\hline Bevantolol (n=536) & 87 & 16.2 & 21 & 3.9 & 28 & 5.2 & 8 & 1.5 & 4 & 0.8 & 5 & 0.9 \\
\hline Bisoprolol (n=49493) & 13995 & 28.3 & 1805 & 3.7 & 4112 & 8.3 & 768 & 1.6 & 511 & 1.0 & 300 & 0.6 \\
\hline Carvedilol (n=38412) & 9456 & 24.6 & 1902 & 5.0 & 3116 & 8.1 & 555 & 1.4 & 423 & 1.1 & 261 & 0.7 \\
\hline Propranolol (n=32854) & 3160 & 9.6 & 542 & 1.7 & 1590 & 4.8 & 480 & 1.5 & 409 & 1.2 & 172 & 0.5 \\
\hline Diltiazem (n=24096) & 4110 & 17.1 & 786 & 3.3 & 1855 & 7.7 & 354 & 1.5 & 233 & 1.0 & 190 & 0.8 \\
\hline Verapamil (n=4803) & 679 & 14.1 & 83 & 1.7 & 340 & 7.1 & 48 & 1.0 & 46 & 1.0 & 41 & 0.9 \\
\hline \multicolumn{13}{|l|}{ Rhythm control } \\
\hline Flecainide (n=13914) & 2657 & 19.1 & 186 & 1.3 & 822 & 5.9 & 217 & 1.6 & 91 & 0.7 & 65 & 0.5 \\
\hline Propafenone (n=14078) & 2530 & 18.0 & 172 & 1.2 & 753 & 5.4 & 236 & 1.7 & 93 & 0.7 & 60 & 0.4 \\
\hline Pilsicainide (n=2890) & 456 & 15.8 & 34 & 1.2 & 141 & 4.9 & 47 & 1.6 & 18 & 0.6 & 21 & 0.7 \\
\hline Amiodarone (n=21976) & 4873 & 22.2 & 930 & 4.2 & 1566 & 7.1 & 280 & 1.3 & 237 & 1.1 & 142 & 0.7 \\
\hline Sotalol (n=1065) & 148 & 13.9 & 31 & 2.9 & 76 & 7.1 & 17 & 1.6 & 4 & 0.4 & 5 & 0.5 \\
\hline Dronedarone $(n=1767)$ & 292 & 16.5 & 57 & 3.2 & 96 & 5.4 & 27 & 1.5 & 4 & 0.2 & 14 & 0.8 \\
\hline
\end{tabular}

CHF, congestive heart failure; MI, myocardial infarction; TIA, transient ischemic attack; ICH, intracranial hemorrhage; GI, gastrointestinal.

Distribution: normal. Reference: The National Health Insurance Service.

Health status

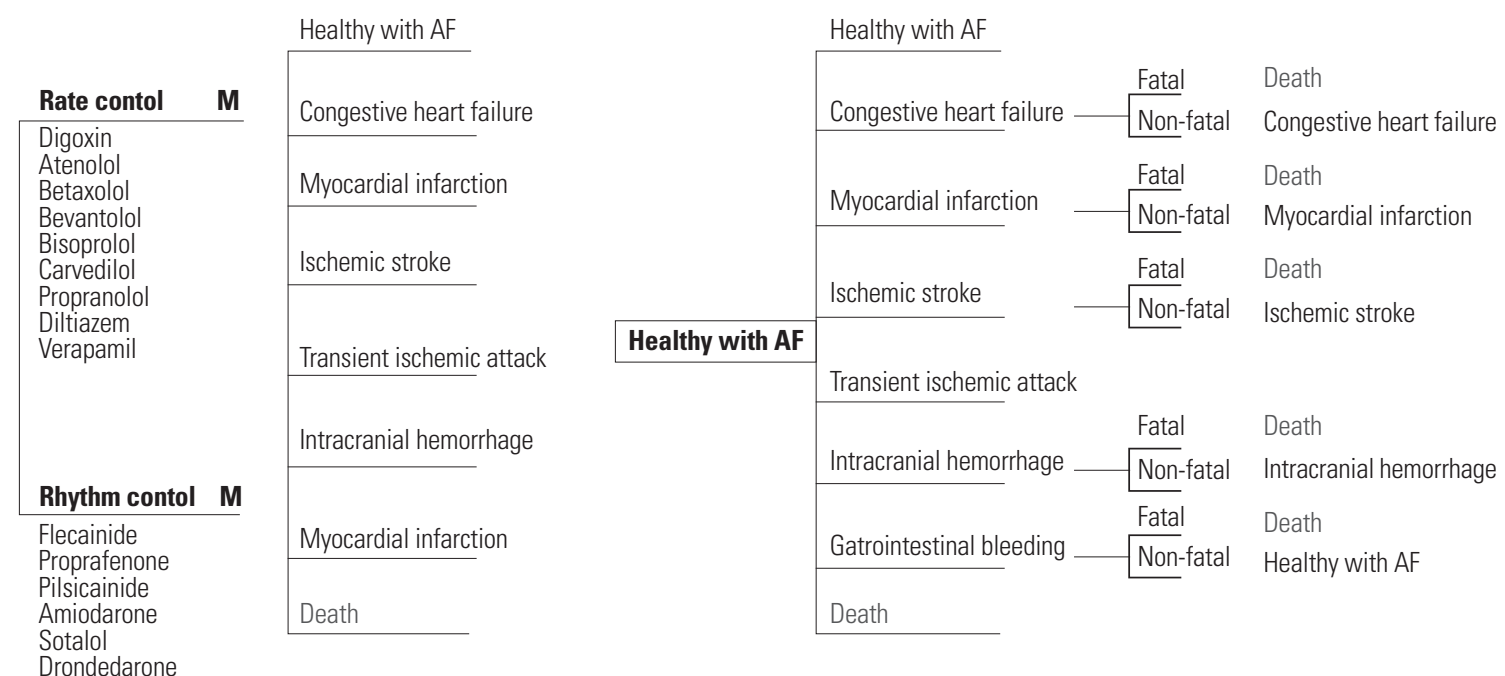

Fig. 1. Decision tree model. The treatment strategies are shown on the left in patients with newly diagnosed atrial fibrillation between January 1,2013 and December 31, 2015 in Korea. Markov node (M) indicates a Markov process with eight health statuses and a cycle length of 1 year until death occurred or the 20-year time horizon was reached. Probabilities of health events depend on the treatment. Patients could die of ischemic stroke, intracranial hemorrhage, myocardial infarction, gastrointestinal bleeding, or other comorbidities. AF, atrial fibrillation. 
similar in all groups, and efficacy was assumed to be relatively constant. To ensure patient follow-up for a lifetime, a cycle length of year and a time horizon of 20 years were used. Each year, the cohort accrued costs and quality-adjusted life years (QALY) depending on which health state they inhabited. The model was built in TreeAge Pro 2012 (TreeAge Software, Inc., Williamstown, MA, USA).

\section{Quality of life estimates}

To measure quality-adjusted survival, QALY values were calculated by multiplying life years by utility scores derived from the medical literature. ${ }^{27,28}$ By definition, death (from any cause) had a QALY of 0 . The utility scores of CHF, MI, ischemic stroke, TIA, fatal GI bleeding, and ICH were 0.7, 0.9, 0.4, 0.8, 0.9, and 0.4 , respectively. The discount rate was set at annual $3 \%$, reflecting the annual inflation rate in Korea. ${ }^{29}$

\section{Cost-effectiveness analysis}

The net cost for each treatment drug by QALY was quantified over a period of 20 years using a societal perspective. The cost consisted of annual drug costs, maintenance costs, and single event costs. Annual drug costs were defined as the drug cost per day during 1 year based on the NHIS database (Supplementary Table 1, only online). The event-related cost was estimated as the average cost of hospitalization for the health event (Supplementary Table 2, only online). We estimated effectiveness (QALY) and the mean cost per tablet and year for the rate-control and rhythm-control groups. QALY and net costs were adjusted in each cycle related to the patients' health states. According to the amount of time a person spent in a health state, QALY and the costs accrued for each Markov state were weighted. Costs are expressed in US dollars, and the cost-effectiveness of individual drugs (rate control and rhythm control) was compared with atenolol through cost-effectiveness ratio (cost per QALY) and incremental cost-effectiveness ratio (ICER), which can be used for informed decision-making when resources are limited. Willing-to-pay was estimated at $\$ 30000$ US/QALY, reflecting the GDP for Korea (US \$29745 in 2017). Korean won (KRW) was converted to US dollars ( $\$ 1$ US=1000 KRW) in this analysis.

\section{RESULTS}

\section{Number of prescriptions for each drug}

During the study period, bisoprolol was the most commonly prescribed drug for rate control $(23.8 \%)$, followed by carvedilol and digoxin (18.11\% and $17.22 \%$, respectively). Betaxolol and bevantolol had the lowest prescription rates $(0.4 \%$ and $0.2 \%$, respectively). Amiodarone was the most commonly prescribed rhythm control drug (39.7\%), followed by flecainide and propafenone (25.7\% and $25.1 \%$, respectively). Sotalol had the lowest prescription rate $(2.0 \%)$, followed by pilsicainide and dronedarone (4.1\% and 3.4\%, respectively).

\section{Incidence of health events}

In an integrated analysis involving all drugs, the number of ischemic strokes per year for bisoprolol was highest (8.3\%), while that for pilsicainide was lowest (4.9\%). The number of TIA, ICH, GI bleeding, MI, and CHF events per year was highest for betaxolol, propranolol, bevantolol, carvedilol, and digoxin (1.7\%, $1.2 \%, 0.9 \%, 5.0 \%$, and $28.6 \%$, respectively), while that for verapamil, dronedarone, propafenone, pilsicainide, and propranolol was lowest $(1.0 \%, 0.2 \%, 0.4 \%, 1.2 \%$, and $9.6 \%$, respectively).

\section{Cost-effectiveness of rate control medications}

Among the rate-control medications, the cost per QALY for propranolol was lowest (\$487/QALY), while that for carvedilol was highest (\$1363/QALY).

Based on base-case assumptions, the average lifetime treatments costs of rate-control drugs and QALY were $\$ 10443$ and 13, respectively. The cost per QALY for atenolol was \$714/QALY. Carvedilol had the highest cost per QALY (\$1363/QALY), while propranolol had the lowest cost per QALY (\$487/QALY). However, at a willingness-to-pay threshold of $\$ 30000$ USD/QALY, all rate control drugs for treating AF were cost-effective. The incremental cost (-\$1499) was lowest and incremental effectiveness (3 QALY) was highest with propranolol, which reflected a more valuable ICER (-\$577/QALY) than that with atenolol (Table 3, Fig. 2, Supplementary Fig. 2, only online).

\section{Cost-effectiveness of rhythm control medications}

Patients taking rhythm-control drugs lived an average of 14 QALY, with average lifetime treatments costs of \$10745. Among the rhythm-control medications, the cost per QALY for pilsicainide was lowest (\$638/QALY), while that for amiodarone was highest (\$986/QALY). Flecainide, propafenone, and dronedarone had costs per QALY of \$834, \$830, and \$824/QALY, respectively. Sotalol and pilsicainide had incremental cost $(\$ 453$ and \$996) and incremental effectiveness (2 and 3 QALY), demonstrating ICER values of \$324/QALY and \$332/QALY, respectively, compared with atenolol. Equivalent to rate-control drugs, the cost-effectiveness thresholds of the rhythm-control drugs in this analysis were lower than $\$ 30000$ per QALY (Table 3, Fig. 3, Supplementary Figs. 3 and 4, only online).

\section{Sensitivity analysis}

Sensitivity analyses were performed to test uncertainty and to confirm the robustness of the results. The varying parameters in the analysis included discount rates of $5 \%$, as well as $20 \%$ increases above previous assumptions for annual drug prices, annual maintenance costs, and costs of health incidents. The sensitivity analysis did not differ from the basic analysis despite changes in the discount rate and cost (Supplementary Tables 3 and 4, only online). 
Min Kim, et al.

Table 3. Projected Costs, QALYs, and ICERs for the Rate- and Rhythm-Control Drugs among Patients Newly Diagnosed with Atrial Fibrillation between January 1, 2013 and December 31, 2015 in Korea

\begin{tabular}{|c|c|c|c|c|c|c|}
\hline & Cost (USD) & OALY & $\begin{array}{c}\text { Cost } \\
\text { per OALY }\end{array}$ & $\begin{array}{l}\text { Incremental cost } \\
\text { (reference atenolol) }\end{array}$ & $\begin{array}{l}\text { Incremental QALY } \\
\text { (reference atenolol) }\end{array}$ & ICER (\$/OALY) \\
\hline \multicolumn{7}{|l|}{ Rate control } \\
\hline Atenolol & 8707 & 12 & 714 & 0 & 0 & 0 \\
\hline Propranolol & 7208 & 15 & 487 & -1499 & 3 & -577 \\
\hline Betaxolol & 8618 & 14 & 611 & -90 & 2 & -4 \\
\hline Verapamil & 9477 & 13 & 718 & 769 & 1 & 769 \\
\hline Diltiazem & 9518 & 13 & 732 & 810 & 1 & 1013 \\
\hline Bevantolol & 10023 & 14 & 732 & 1315 & 2 & 877 \\
\hline Carvedilol & 13084 & 10 & 1363 & 4376 & -2 & -1683 \\
\hline Digoxin & 13487 & 11 & 1237 & 4780 & -1 & -3677 \\
\hline Bisoprolol & 13868 & 13 & 1101 & 5161 & 1 & 12903 \\
\hline \multicolumn{7}{|l|}{ Rhythm control } \\
\hline Sotalol & 9161 & 14 & 674 & 453 & 2 & 324 \\
\hline Pilsicainide & 9704 & 15 & 638 & 996 & 3 & 332 \\
\hline Flecainide & 10931 & 13 & 834 & 2224 & 1 & 2471 \\
\hline Propafenone & 11282 & 14 & 830 & 2574 & 2 & 1839 \\
\hline Dronedarone & 11457 & 14 & 824 & 2750 & 2 & 1618 \\
\hline Amiodarone & 11931 & 12 & 986 & 3224 & 0 & -32238 \\
\hline
\end{tabular}

OALY, quality-adjusted life year; ICER, incremental cost-effectiveness ratio; USD, US dollars (\$).

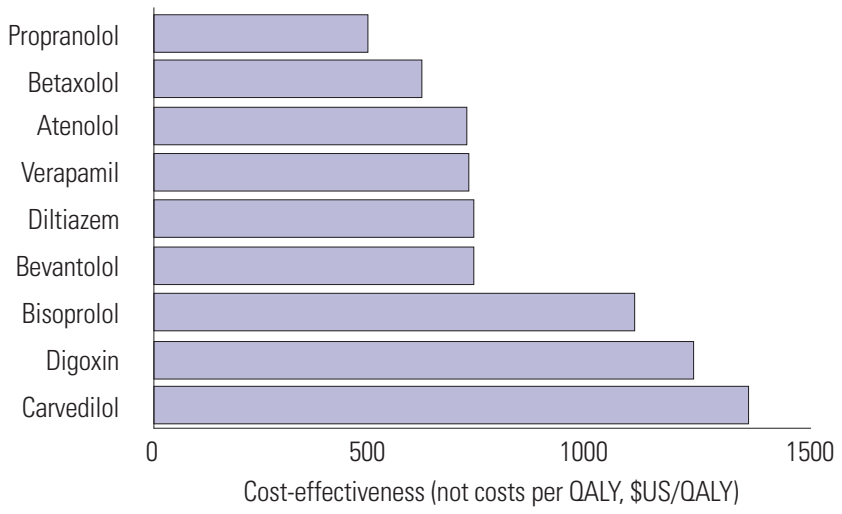

Fig. 2. Cost-effectiveness (bars) of rate-control drugs in patients with newly diagnosed atrial fibrillation between January 1, 2013 and December 31, 2015 in Korea. All drugs remained cost-effective at a willingnessto-pay threshold of $\$ 30000$ per quality-adjusted life year (QALY).

\section{DISCUSSION}

Our Markov chain Monte Carlo model showed that in patients treated with rate-control drugs, propranolol may be a cost-effective alternative to other agents in Korean patients with AF. Among rate-control drugs, propranolol showed the highest QALY and the lowest net cost, compared with atenolol. In patients taking rhythm-control drugs, sotalol and pilsicainide had lower net costs and increased QALYs, compared with atenolol. The present analysis demonstrated that propranolol, sotalol, and pilsicainide may be preferred alternatives based on costs among rate-control and rhythm-control drugs of use in Korea.

Previous studies have described a non-significant trend to-

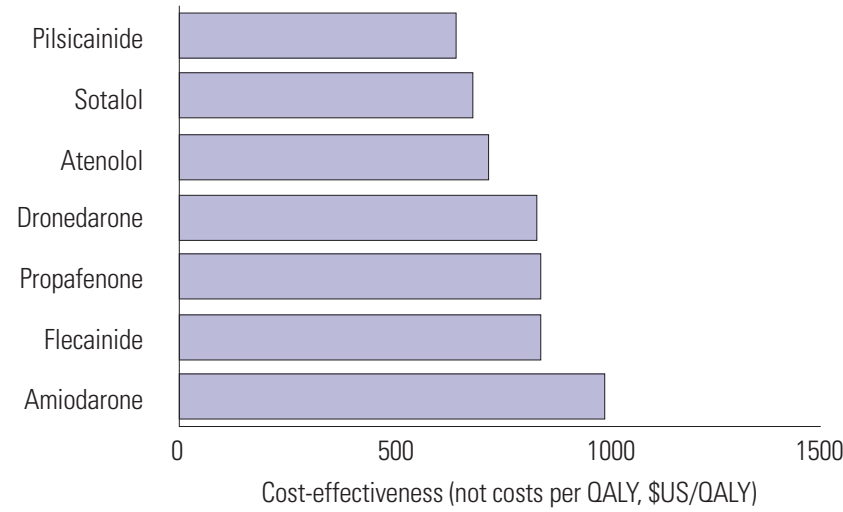

Fig. 3. Cost-effectiveness (bars) of rhythm-control drugs in patients with newly diagnosed atrial fibrillation between January 1, 2013 and December 31, 2015 in Korea. All drugs remained cost-effective at a willingnessto-pay threshold of $\$ 30000$ per quality-adjusted life years (OALY).

ward reduced survival in patients with $\mathrm{AF}$ who attempt rhythm control, compared with rate control. ${ }^{21-23,30,31}$ Since economic factors may play a considerable role in selecting treatment options, several authors have investigated the cost-effectiveness of rhythm- versus rate-control strategies for treating $\mathrm{AF}^{24,32-34}$ Eckman, et al. ${ }^{32}$ showed that cardioversion followed by the use of warfarin and amiodarone was the most effective strategy among several antiarrhythmic and antithrombotic treatment options. Catherwood, et al..$^{33}$ found that cardioversion with or without antiarrhythmic drugs was more effective and less costly than rate-control drugs. Hagens, et al. ${ }^{34}$ demonstrated that treatment costs were higher for rhythm-control than rate-control drugs due to the higher costs of electrical cardioversion, 
hospital admission, and medication in patients with persistent AF. However, these studies were limited by the lack of randomized data on efficacy and resource use. Marshall, et al. ${ }^{24}$ performed an economic analysis of the Atrial Fibrillation Followup Investigation of Rhythm Management (AFFIRM) ${ }^{21}$ results and found non-significant differences in mean survival time, although treatment costs were always higher in the rhythm control group. In that study, the drug cost per day was greater for all of the rhythm-control drugs than the rate-control drugs. The authors compared resource use data, including medications, hospital visits, cardiac procedures, and short-stay and emergency department visits.

Here, we estimated the effectiveness (QALY) and mean net cost per year for individual rate- and rhythm-control drugs. Although bisoprolol and amiodarone were the most frequently prescribed drugs during the study period, we found that propranolol was the more cost-effective rate-control drug and that sotalol and pilsicainide were the most cost-effective rhythmcontrol drugs. These findings were based on a comprehensive calculation of net costs, incremental costs, QALY, and ICER.

Our study has several limitations. First, because details on the quantification and doses of the prescribed medications and treatment adherence were not available, we assumed that each medication was taken properly at standardized doses. Therefore, our data did not accurately reflect real life efficacy and safety because participants may exhibit superior medication adherence. Any misclassification would probably affect underor overestimation of the true difference in drugs costs. Second, we only analyzed health events of ischemic stroke, TIA, ICH, GI bleeding, MI, and CHF using Korean NHIS data for 3 years. These data do not fully reflect the analysis contents of the study in real world practice. According to limited data from the Korean NHIS, we did not further assess the association between treatment strategy and other resource events or procedures, such as cardioversion or pacemaker implantation. Third, patients who took two or more drugs were assigned to each drug. One patient could be included in a drug category more than twice. Because drug-based analysis was performed, it was not possible to estimate the overall medications costs for each patient. Fourth, with a mean age of 66 years, our patients were relatively old for patients with AF. Thus, while our results can be applied to AF patients in general, they probably cannot be generalized to younger patients with AF. Fifth, we assumed that any non-fatal GI bleeding would result in a healthy state. This may not always be the case and would likely be based on individual patient factors. Sixth, rhythm control strategies of guidelines in AF recommend specific class drugs depending on whether a patient has structural heart disease. However, we did an integrated analysis of rhythm-control drugs, regardless of the presence of cardiac structural abnormality. Therefore, direct comparison of cost-effectiveness among rhythm control drugs was not available in our study. Finally, much more work is needed to perform a cost-effectiveness analysis that can im- prove health outcomes and save system-wide costs.

In conclusion, propranolol and pilsicainide were found to be cost-effective in patients with $\mathrm{AF}$ in Korea, assuming that drug usage or compliance is the same. Notwithstanding, in addition to cost-effectiveness, drug selection ought to consider drug safety, patient preference, and side effects.

\section{ACKNOWLEDGEMENTS}

This study was supported by a research grant from the Basic Science Research Program through the National Research Foundation of Korea funded by the Ministry of Health \& Welfare (HI15C1200).

\section{AUTHOR CONTRIBUTIONS}

Conceptualization: All authors. Data curation: Changsoo Kim and Woojin Kim. Formal analysis: All authors. Funding acquisition: Changsoo Kim and Boyoung Joung. Investigation: All authors. Methodology: All authors. Project administration: All authors. Resources: All authors. Software: All authors. Supervision: Changsoo Kim and Boyoung Joung. Validation: All authors. Visualization: All authors. Writing - original draft: Boyoung Joung and Min Kim. Writing-review \& editing: All authors.

\section{ORCID iDs}

$\begin{array}{ll}\text { Min Kim } & \text { https://orcid.org/0000-0002-8132-9873 } \\ \text { Woojin Kim } & \text { https://orcid.org/0000-0001-5520-4228 } \\ \text { Changsoo Kim } & \text { https://orcid.org/0000-0003-1180-1703 } \\ \text { Boyoung Joung } & \text { https://orcid.org/0000-0001-9036-7225 }\end{array}$

\section{REFERENCES}

1. Braunwald E. Cardiovascular Medicine at the turn of the millennium: triumphs, concerns, and opportunities. N Engl J Med 1997; 337:1360-9.

2. Benjamin EJ, Wolf PA, D’Agostino RB, Silbershatz H, Kannel WB, Levy D. Impact of atrial fibrillation on the risk of death: the Framingham Heart Study. Circulation 1998;98:946-52.

3. Kirchhof P, Benussi S, Kotecha D, Ahlsson A, Atar D, Casadei B, et al. 2016 ESC Guidelines for the management of atrial fibrillation developed in collaboration with EACTS. Eur Heart J 2016;37:2893962.

4. January CT, Wann LS, Alpert JS, Calkins H, Cigarroa JE, Cleveland JC Jr, et al. 2014 AHA/ACC/HRS guideline for the management of patients with atrial fibrillation: a report of the American College of Cardiology/American Heart Association Task Force on Practice Guidelines and the Heart Rhythm Society. J Am Coll Cardiol 2014; 64:e1-76.

5. Stewart S, Hart CL, Hole DJ, McMurray JJ. A population-based study of the long-term risks associated with atrial fibrillation: 20year follow-up of the Renfrew/Paisley study. Am J Med 2002;113: 359-64.

6. Maisel WH, Stevenson LW. Atrial fibrillation in heart failure: epidemiology, pathophysiology, and rationale for therapy. Am J Cardiol 2003;91(6A):2D-8D.

7. Wolf PA, Abbott RD, Kannel WB. Atrial fibrillation as an independent risk factor for stroke: the Framingham Study. Stroke 1991; 
22:983-8.

8. Kim TH, Yang PS, Uhm JS, Kim JY, PakHN, Lee MH, et al. CHA2DS2VASc Score (Congestive heart failure, hypertension, age $\geq 75$ [doubled], diabetes mellitus, prior stroke or transient ischemic attack [doubled], vascular disease, age 65-74, female) for stroke in Asian patients with atrial fibrillation: a Korean nationwide sample cohort study. Stroke 2017;48:1524-30.

9. Aronow WS. Management of the older person with atrial fibrillation. J Gerontol A Biol Sci Med Sci 2002;57:M352-63.

10. Go AS, Hylek EM, Phillips KA, Chang Y, Henault LE, Selby JV, et al. Prevalence of diagnosed atrial fibrillation in adults: national implications for rhythm management and stroke prevention: the AnTicoagulation and risk factors in atrial fibrillation (ATRIA) study. JAMA 2001;285:2370-5.

11. Lloyd-Jones DM, Wang TJ, Leip EP, Larson MG, Levy D, Vasan RS, et al. Lifetime risk for development of atrial fibrillation: the Framingham Heart Study. Circulation 2004;110:1042-6.

12. Miyasaka Y, Barnes ME, Gersh BJ, Cha SS, Bailey KR, Abhayaratna WP, et al. Secular trends in incidence of atrial fibrillation in Olmsted County, Minnesota, 1980 to 2000, and implications on the projections for future prevalence. Circulation 2006;114:119-25.

13. Heeringa J, van der Kuip DA, Hofman A, Kors JA, van Herpen G, Stricker BH, et al. Prevalence, incidence and lifetime risk of atrial fibrillation: the Rotterdam study. Eur Heart J 2006;27:949-53.

14. Son MK, Lim NK, Cho MC, Park HY. Incidence and risk factors for atrial fibrillation in Korea: the National Health Insurance Service Database (2002-2010). Korean Circ J 2016;46:515-21.

15. Kim D, Yang PS, Jang E, Yu HT, Kim TH, Uhm JS, et al. 10-year nationwide trends of the incidence, prevalence, and adverse outcomes of non-valvular atrial fibrillation nationwide health insurance data covering the entire Korean population. Am Heart J 2018; 202:20-6.

16. Lee H, Kim TH, Baek YS, Uhm JS, Pak HN, Lee MH, et al. The trends of atrial fibrillation-related hospital visit and cost, treatment pattern and mortality in Korea: 10-year nationwide sample cohort data. Korean Circ J 2017;47:56-64.

17. Lee S, Anglade MW, Pham D, Pisacane R, Kluger J, Coleman CI. Cost-effectiveness of rivaroxaban compared to warfarin for stroke prevention in atrial fibrillation. Am J Cardiol 2012;110:845-51.

18. O'Brien CL, Gage BF. Costs and effectiveness of ximelagatran for stroke prophylaxis in chronic atrial fibrillation. JAMA 2005;293: 699-706.

19. Shah SV, Gage BF. Cost-effectiveness of dabigatran for stroke prophylaxis in atrial fibrillation. Circulation 2011;123:2562-70.

20. Kim H, Kim H, Cho SK, Kim JB, Joung B, Kim C. Cost-effectiveness of rivaroxaban compared to warfarin for stroke prevention in atrial fibrillation. Korean Circ J 2019;49:252-63.

21. Wyse DG, Waldo AL, DiMarco JP, Domanski MJ, Rosenberg Y, Schron EB, et al. A comparison of rate control and rhythm control in patients with atrial fibrillation. N Engl J Med 2002;347:1825-33.

22. Van Gelder IC, Hagens VE, Bosker HA, Kingma JH, Kamp O, Kingma T, et al. A comparison of rate control and rhythm control in patients with recurrent persistent atrial fibrillation. $\mathrm{N}$ Engl J Med 2002;347:1834-40.

23. Choi YJ, Kang KW, Kim TH, Cha MJ, Lee JM, Park J, et al. Comparison of rhythm and rate control strategies for stroke occurrence in a prospective cohort of atrial fibrillation patients. Yonsei Med J 2018;59:258-64.

24. Marshall DA, Levy AR, Vidaillet H, Fenwick E, Slee A, Blackhouse $\mathrm{G}$, et al. Cost-effectiveness of rhythm versus rate control in atrial fibrillation. Ann Intern Med 2004;141:653-61.

25. Lee HY, Yang PS, Kim TH, Uhm JS, Pak HN, Lee MH, et al. Atrial fibrillation and the risk of myocardial infarction: a nation-wide propensity-matched study. Sci Rep 2017;7:12716.

26. Lee SS, Kong KA, Kim D, Lim YM, Yang PS, Yi JE, et al. Clinical implication of an impaired fasting glucose and prehypertension related to new onset atrial fibrillation in a healthy Asian population without underlying disease: a nationwide cohort study in Korea. Eur Heart J 2017;38:2599-607.

27. Sullivan PW, Ghushchyan V. Preference-based EQ-5D index scores for chronic conditions in the United States. Med Decis Making 2006;26:410-20.

28. Gage BF, Cardinalli AB, Owens DK. The effect of stroke and stroke prophylaxis with aspirin or warfarin on quality of life. Arch Intern Med 1996;156:1829-36.

29. Weinstein MC, Siegel JE, Gold MR, Kamlet MS, Russell LB. Recommendations of the panel on cost-effectiveness in health and medicine. JAMA 1996;276:1253-8.

30. Hohnloser SH, Kuck KH, Lilienthal J. Rhythm or rate control in atrial fibrillation--Pharmacological Intervention in Atrial Fibrillation (PIAF): a randomised trial. Lancet 2000;356:1789-94.

31. Carlsson J, Miketic S, Windeler J, Cuneo A, Haun S, Micus S, et al. Randomized trial of rate-control versus rhythm-control in persistent atrial fibrillation: the Strategies of Treatment of Atrial Fibrillation (STAF) study. J Am Coll Cardiol 2003;41:1690-6.

32. Eckman MH, Falk RH, Pauker SG. Cost-effectiveness of therapies for patients with nonvalvular atrial fibrillation. Arch Intern Med 1998;158:1669-77.

33. Catherwood E, Fitzpatrick WD, Greenberg ML, Holzberger PT, Malenka DJ, Gerling BR, et al. Cost-effectiveness of cardioversion and antiarrhythmic therapy in nonvalvular atrial fibrillation. Ann Intern Med 1999;130:625-36.

34. Hagens VE, Vermeulen KM, TenVergert EM, Van Veldhuisen DJ, Bosker HA, Kamp O, et al. Rate control is more cost-effective than rhythm control for patients with persistent atrial fibrillation- -results from the RAte Control versus Electrical cardioversion (RACE) study. Eur Heart J 2004;25:1542-9. 